\title{
CABECEIRAS DE DRENAGEM DA BACIA DO RIO QUATORZE - FORMAÇÃO SERRA GERAL (SW DO PARANÁ): DISTRIBUIÇÃO ESPACIAL, PROPRIEDA- DES MORFOLÓGICAS E CONTROLE ESTRUTURAL
}

\author{
Drainage Headboards of the Rio Quatorze Base - Serra Geral Formation \\ (Southwest of Paraná): space distribution, morphological properties and \\ structural control
}

Julio C. PAISANI ${ }^{1}$

Marga E. PONTELLI ${ }^{2}$

Francielli GEREMIA ${ }^{3}$

\begin{abstract}
RESUMO
O artigo apresenta resultados sobre a distribuição espacial, propriedades morfológicas e controle estrutural em cabeceiras de drenagem da bacia do Rio Quatorze, Formação Serra Geral - SW/Paraná. A distribuição espacial foi encaminhada por domínio geomorfológico e revelou que as cabeceiras estão, em sua maioria (76,32\%), na superfície aplainada de topo. Caracterizou-se o tipo de eixo de drenagem e a forma dessas feições, definidas pelo índice de circularidade. Verificase que as cabeceiras de drenagem são feições circulares e rasas. Constata-se que a maioria das cabeceiras $(61,05 \%)$ é controlada por fraturas, diante da comparação da orientação de família de fraturas da área versus orientação dos eixos de drenagem dessas feições e a orientação de alinhamentos de cabeceiras.
\end{abstract}

Palavras-chave:

Cabeceira de drenagem; Formação Serra Geral; controle estrutural.

\begin{abstract}
The article introduces results about the space distribution, morphological properties and structural control in drainage headboards of the Rio Quartoze base, Serra General Formation - Southwest of Paraná. The space distribution was sent by geomorphological domain and revealed that the headboards are in their majority $(76,32 \%)$ on the top flattened surface. It characterized the kind of the drainage axis and these features form, defined by the circularity index. It verifies that the drainage headboards are circular and shallow features. It verifies that the most headboards $(61,05 \%)$ is controlled by family orientation fractures comparison of the area versus drainage axis orientation of these features and the headboards alignmts orientation.
\end{abstract}

\section{Key-words:}

Drainage headboard; Serra General formation; structural control.

\footnotetext{
1 Universidade Estadual do Oeste do Paraná - Campus Francisco Beltrão, Prof. Adjunto do Colegiado de Geografia. E-mail: juliopaisani@hotmail.com

2 Universidade Estadual do Oeste do Paraná - Campus Francisco Beltrão, Prof. Adjunta do Colegiado de Geografia. E-mail: mpontelli@hotmail.com

3 Universidade Estadual do Oeste do Paraná - Campus Francisco Beltrão, Acadêmica do Curso de Geografia e Bolsista PIBIC/ CNPq/Unioeste. E-mail: francieligeremia@bol.com.br
} 


\section{INTRODUÇÃO}

O termo cabeceira de drenagem se refere à área côncava situada a montante de canal de primeira ordem (PAISANI; OLIVEIRA, 1999). Na literatura, essa feição também é designada de bacia de ordem zero, microbacia, vale não canalizado, cabeceira de vale, hollow, anfiteatro, concavidade, rampa e dambo (MEIS; MONTEIRO, 1979; TSUKAMOTO, 1982; MONTGOMERY; DIETRICH, 1989; MOURA et al., 1991; AVELAR; COELHO NETTO, 1992; DIETRICH; DUNNE, 1993; THOMAS, 1994; OLIVEIRA, 1992; COELHO NETTO, 2003; BIGARELLA et al., 2003). Nas últimas décadas, as cabeceiras de drenagem têm recebido atenção de estudos hidrológicos em diferentes países, inclusive no Brasil, visando compreender os processos responsáveis pela inicialização de canais hidrográficos e desenvolvimento de incisões erosivas (ex. KIRKBY, 1978; OLIVEIRA; MEIS, 1985; MONTGOMERY; DIETRICH, 1989; FERNANDES, 1990; OLIVEIRA, 1992; DIETRICH; DUNNE, 1993; CAMARGO, 1998; PAISANI; OLIVEIRA, 1999; 2001; PAISANI, 2002).

Igual atenção não tem recebido o estudo da origem e evolução dessas feições geomorfológicas e de suas formações superficiais. No Brasil, há décadas, a caracterização das formações superficiais de cabeceiras de drenagem tem se concentrado no médio vale do Rio Paraíba do Sul (SP/RJ), cujo substrato é constituído por rochas cristalofilianas. Os estudos nessa área revelaram espessos pacotes de sedimentos colúvioaluvionares intercalados por paleossolos, que atesta evolução cíclica para essas feições, com predomínio de processos erosi-vos-deposicionais mecânicos (ex. MEIS; MONTEIRO, 1979; MOURA et al., 1991; MELLO, 1992).

Cabeceiras de drenagem com formações superficiais constituídas de sedimentos colúvio-aluvionares não são exclusivas do médio vale do Rio Paraíba do Sul, sendo identificadas também em vales do Segundo Planalto Paranaense e em superfície análoga no Estado de Santa Catarina, cujo substrato caracteriza-se, respectivamente, por rochosas sedimentares e vulcanosedimentares (CAMARGO, 1998; OLIVEIRA; PEREIRA, 1998; PAISANI; OLIVEIRA, 1998; OLIVEIRA et al., 2001; MELO et al., 2003).

Se por um lado as cabeceiras de drenagem dessas regiões evoluiram sob ação de processos erosivos controlados pela geodinâmica externa, por outro sua origem foi pouco explorada. No caso do médio vale do Rio Paraíba do Sul são reconhecidas duas possibilidades para a origem das cabeceiras de drenagem: 1) processos gravitacionais comandados pela dinâmica fluvial e 2) processos hidrológicos comandados por fraturamentos - feições resultantes da geodinâmica interna
(AVELAR; COELHO NETTO, 1992; COELHO NETTO, 2003). Em efeito, a gênese e evolução de cabeceiras de drenagem é questão em aberto e deve variar conforme as características geológicas e climáticas de cada região.

O grupo de pesquisa "Gênese e Evolução de Superfícies Geomórficas e Formações Superficiais", formado na Unioeste e cadastrado no CNPq, vem se interessando pelos fatores responsáveis pelo desenvolvimento de cabeceiras de drenagem em redes hidrográficas estabelecidas sobre terreno vulcânico da região sudoeste do Paraná, bem como pelos processos responsáveis pela sua evolução. Os trabalhos estão sendo desenvolvidos na bacia do Rio Quatorze, área-piloto no sistema hidrográfico do Rio Marrecas, e já permitem apresentar a distribuição espacial, propriedades morfológicas e identificar se há controle estrutural na sua origem. O presente artigo sistematiza tais informações, buscando colaborar na compreensão da origem e evolução dessas feições geomorfológicas nos terrenos vulcânicos da Formação Serra Geral.

\section{CARACTERÍSTICAS GERAIS DA ÁREA DE ESTUDO}

A Bacia do Rio Quatorze exibe $112,75 \mathrm{~km}^{2}$ de área e drena a margem esquerda do sistema hidrográfico do Rio Marrecas (Figura 1). A área ainda carece de informações climáticas na escala da bacia hidrográfica, sabese apenas que se insere na zona climática subtropical mesotérmica úmida que se estende pela maior parte do sudoeste do Paraná (MARTINS, 2003).

A bacia promove a denudação de rochas vulcânicas básicas intermediárias resultantes de derrames de lava Juro/Eo-Cretáceo (FODOR et al., 1989; NARDY et al., 1993), pertencentes à Formação Serra Geral (SCHNEIDER et al., 1974). No Paraná, a formação se estende por unidade fisiográfica referida por Maack (1981) como Terceiro Planalto Paranaense (Figura 1).

\section{MÉTODO}

A individualização de cabeceiras de drenagem na área de estudo se baseou no Mapa Morfoescultural elaborado da bacia, gerado por Geremia e Paisani (2005), escala 1:24.000, exibindo cabeceiras de drenagem, além de depressões fechadas, patamares, degraus estruturais, dentre outras feições. As cabeceiras de drenagem individualizadas no mapa morfoescultural não correspondem ao total de cabeceiras da área de estudo, mas sim às feições côncavas com dimensões perceptíveis em fotografias aéreas escala de 1:25.000. A análise da distribuição espacial das cabeceiras, na área de estudo, 


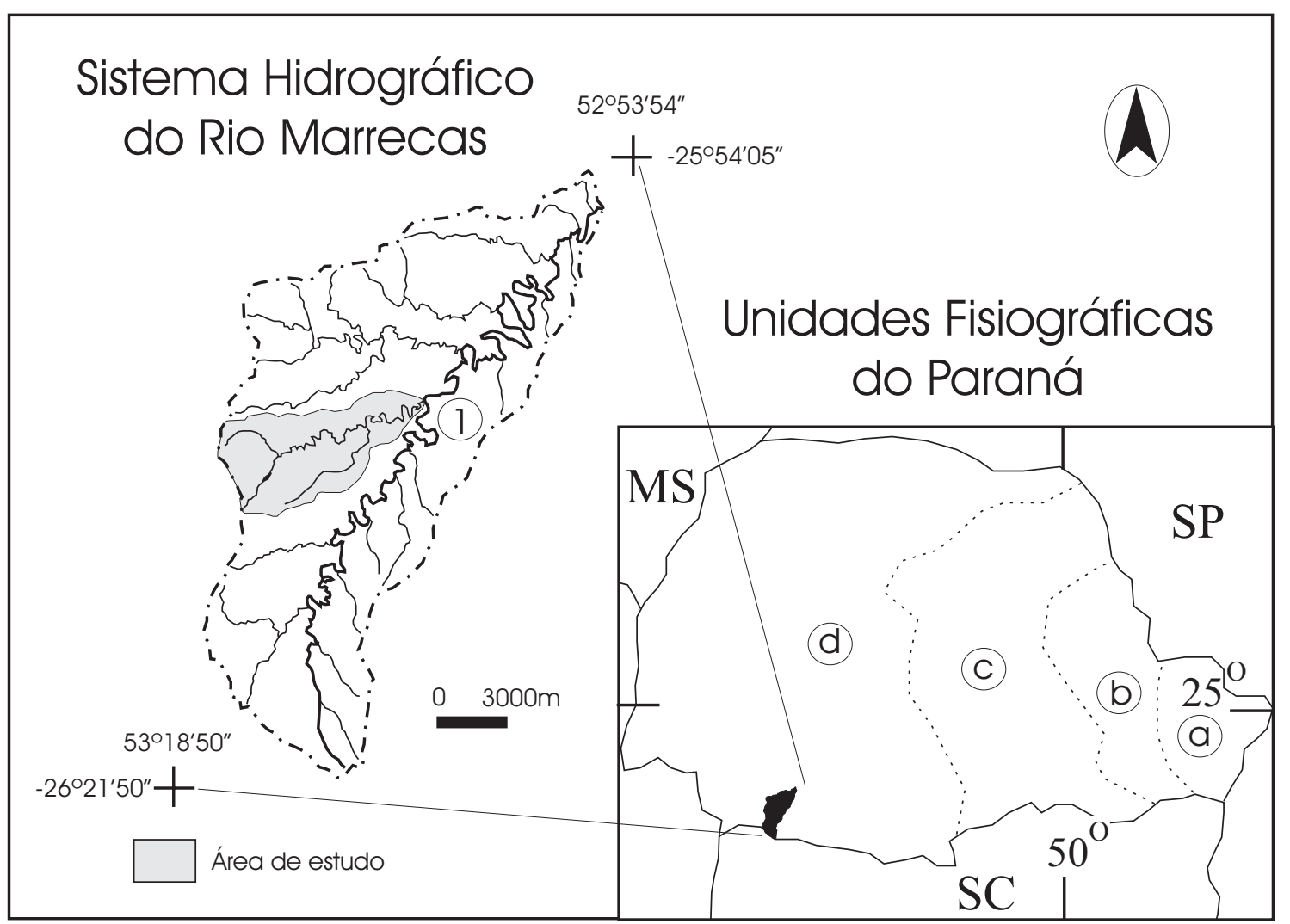

FIGURA 1 - UNIDADES FISIOGRÁFICAS DO PARANÁ E O SISTEMA HIDROGRÁFICO DO RIO MARRECAS COM A LOCALIZAÇÃO DA BACIA DO RIO QUATORZE. (1) RIO MARRECAS. (A) SERRA DO MAR/LITORAL. (B) PRIMEIRO PLANALTO. (C) SEGUNDO PLANALTO. (D) TERCEIRO PLANALTO, DOMINADO POR ROCHAS VULCÂNICAS DA FORMAÇÃO SERRA GERAL

foi encaminhada seguindo-se os domínios geomorfológicos identificados a partir das informações geomorfológicas do mapa morfoescultural e perfis topográficos estabelecidos em carta topográfica SG 22-Y-A-II-2, escala 1:50.000.

Procedeu-se a caracterização morfológica das cabeceiras de drenagem, descrevendo-se o tipo de eixo de drenagem e a forma dessas feições. Os eixos de drenagem foram classificados em suaves e íngremes, baseados em observações de fotografias aéreas e de campo. Como as cabeceiras de drenagem são entendidas, por definição, como bacias côncavas de ordem zero, optou-se pelo uso do índice de circularidade (Equação 1) para definir a forma dessas feições.

$$
\text { Equação 1: IC = A \Ac, }
$$

onde $\mathrm{IC}=$ índice de circularidade; $\mathrm{A}$ = área da cabeceira de drenagem; $A c$ = área de um círculo com mesmo perímetro da cabeceira de drenagem.

Esse índice é muito utilizado na definição da forma de bacias hidrográficas de ordens hierárquicas superiores (ex. CHRISTOFOLETTI, 1969; CHORLEY;
KENNEDY, 1971; CHRISTOFOLETTI; PEREZ FILHO, 1975; CHRISTOFOLETTI, 1980; PAISANI, 1995; ALVES; CASTRO, 2003). Aplicou-se o índice de circularidade medindo-se a área $\left(\mathrm{km}^{2}\right)$ e o perímetro $(\mathrm{km})$ das cabeceiras de drenagem, utilizando-se, respectivamente, planímetro polar e curvímetro analógico, ambos cedidos pela Emater-Fco Beltrão. Os valores mensurados foram ordenados em sete classes estabelecidas por critérios estatísticos, conforme Gerardi e Silva (1981).

O controle estrutural no estabelecimento de cabeceiras de drenagem refere-se a fraturamentos, feições mais expressivas na determinação da disposição de canais de drenagem e em especial de cabeceiras de drenagem (LOCZY; LADEIRA, 1980; SCHEIDEGGER, 1986; AVELAR; COELHO NETTO, 1992). A identificação de controle estrutural na determinação da origem das cabeceiras de drenagem se baseou na comparação entre orientação de família de fraturas na área levantada por Paisani et al. (submetido) versus a orientação dos eixos de drenagem dessas feições, conforme Avelar e Coelho Netto (1992), e a orientação de alinhamentos de cabeceiras de drenagem. $\mathrm{O}$ alinhamento das 
cabeceiras também é entendido como indicativo de controle estrutural por fraturamentos, pois registram-se casos de depressões fechadas alinhadas que são controladas por esse tipo de feição geológica (PETRI, 1972; LÖFFLER, 1978; FILIZOLA; BOULET, 1996). Os alinhamentos das cabeceiras foram medidos na versão digital do Mapa Morfoescultural gerado por Geremia e Paisani (2005), utilizando-se ferramentas de desenho do software Corel Draw 10.

Pensou-se em utilizar a classificação de cabeceiras estruturais e não estruturais, como observado no médio vale do Rio Paraíba do Sul, por Avelar e Coelho Netto (1992), porém, além das limitações do método aplicado para verificar esse controle, constata-se que as propriedades morfológicas das cabeceiras da área de estudo são similares, não permitindo distinguir essas classes.

\section{DISTRIBUIÇÃO ESPACIAL}

Geremia e Paisani (2005) individualizaram 190 cabeceiras de drenagem na Bacia do Rio Quatorze. As cabeceiras de drenagem se distribuem por dois domíni- os geomorfológicos: superfície aplainada de topo e fundo de vale dissecado (Figura 2). Registram-se 145 cabeceiras no domínio superfície aplainada de topo $(76,32 \%)$ e 45 cabeceiras no fundo de vale dissecado $(23,68 \%)$. Além das cabeceiras predominarem na superfície aplainada de topo, verifica-se que essas feições ocorrem em maior número junto aos divisores norte e sul no médio vale do Rio Quatorze (Figura 2).

A superfície aplainada de topo se estende principalmente do médio ao alto curso do Rio Quatorze, entre as cotas de 800 e $700 \mathrm{~m}$, exibindo relevos residuais (inselbergs) em diferentes altitudes, a exemplo 938, 825 e 789 m. Esse fenômeno ainda é mal compreendido, mas pode indicar antigas superfícies aplainadas geradas por mudanças climáticas ou por levantamento crustal de blocos falhados durante o cenozóico (BIGARELLA et al., 1965; PENCK, 1953). Nesse domínio é comum degraus estruturais, depressões fechadas e cabeceiras de drenagem. As últimas imprimem à unidade morfologia suavemente ondulada, lembrando colinas suaves (coxilhas).

O fundo de vale dissecado se caracteriza por vales predominantemente abertos de fundo chato, com escalonamento tanto de degraus estruturais quanto de

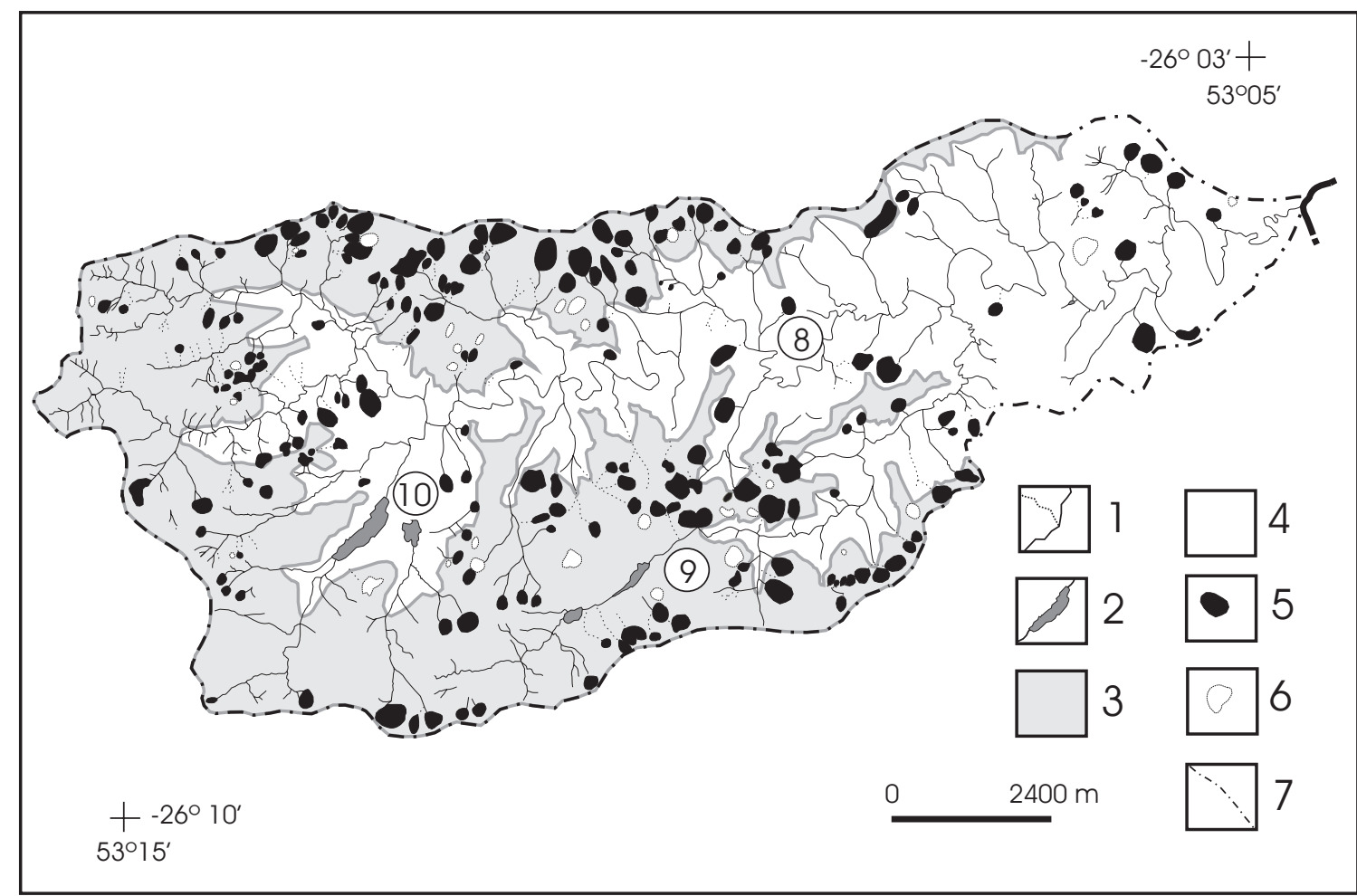

FIGURA 2 - DISTRIBUIÇÃO ESPACIAL DE CABECEIRAS DE DRENAGEM NOS DOMÍNIOS GEOMORFOLÓGICOS DA BACIA DO RIO QUATORZE. (1) DRENAGEM PERENE E EFÊMERA. (2) AÇUDE. (3) SUPERFÍCIE APLAINADA DE TOPO. (4) FUNDO DE VALE DISSECADO. (5) CABECEIRAS DE DRENAGEM. (6) DEPRESSÕES FECHADAS. (7) DIVISORES D'ÁGUA. (8) RIO QUATORZE. (9) RIO LAJEADO GRANDE. (10) ALVÉOLO 
relevos residuais, bem como anfiteatros de variadas dimensões. Destaca-se, nessa unidade, extenso alvéolo situado no alto curso do Rio Quatorze, que imprime nível de base local favorecendo a sedimentação fluvial em setor da bacia onde se esperava máxima erosão e transporte de sedimentos (Figura 2). Esse fenômeno também é mal compreendido e pode estar relacionado à exumação de derrame basáltico mais resistente à erosão, por exemplo basalto maciço abaixo do amigdaloidal.

\section{PROPRIEDADES MORFOLÓGICAS}

As cabeceiras de drenagem são geralmente concavidades rasas, com eixos de drenagem individualizáveis como suaves e íngremes. Cabeceiras com eixo de drenagem suave se encontram tanto na superfície aplainada de topo quanto no fundo de vale dissecado. Cabeceiras com eixo de drenagem íngreme ocorrem nos locais de ruptura de declive entre patamares, em ambos os domínios geomorfológicos. Analisando as fotografias aéreas verifica-se maior ocorrência na área de estudo de cabeceiras com eixo de drenagem suave (Tabela 1).

As cabeceiras de drenagem da bacia do Rio Quatorze aparentam ser circulares, como as depressões fechadas identificadas na área. Aplicou-se o índice de circularidade, medindo-se a área e o perímetro das cabeceiras. A área das cabeceiras de drenagem varia entre 0,02 a $0,91 \mathrm{~km}^{2}$, em média mostra-se com $0,31 \mathrm{~km}^{2}$, enquanto que o perímetro variou de $0,05 \mathrm{a}$ $0,73 \mathrm{~km}^{2}$, em média $0,24 \mathrm{~km}^{2}$.

A finalidade do índice de circularidade é comparar a forma de uma dada bacia, nesse caso a forma da cabeceira de drenagem, com a de um círculo. Os valores do índice podem variar de 0,01 a 1,00, em que cabeceiras com valores mais próximos de 1,00 indicam cabeceiras com forma próxima a de um círculo, e valores iguais a este correspondem a cabeceiras circulares. Para a área de estudo, obteve-se valores do índice de circularidade variando entre 0,30 a 1,0, distribuídos em sete classes (Figura 3). Tomou-se o intervalo de classes entre 0,51-0,60 e 0,91-1,00 como demarcador de cabeceiras com forma mais próxima à circular. Com a distribuição de freqüência dos valores do índice verifica-se que $92,51 \%$ estão no intervalo indicado (Figura 3), sugerindo que a maioria das 190 cabeceiras levantadas mostram-se com forma circular. Essa característica também foi verificada na aplicação do índice para estabelecer a forma de depressões fechadas, sugerindo que fatores similares podem estar determinando a gênese de depressões fechadas e cabeceiras de drenagem na área de estudo (PAISANI; GEREMIA, 2005).

No geral, as cabeceiras de drenagem da área de estudo são rasas, circulares e com eixo de drenagem suave.

\section{CONTROLE ESTRUTURAL}

A bacia do Rio Quatorze, assim como a maioria das bacias da margem esquerda do Rio Marrecas ( $\mathrm{Fi}-$ gura 1), desenvolveu-se sobre bloco soerguido de estrutura de falha suavemente basculado para NE (PAISANI et al., 2005). A linha de falha é responsável pela orientação do Rio Marrecas, o qual exibe seguimentos dispostos na direção $\mathrm{N} 46^{\circ} \mathrm{E}$. Acredita-se que essa estrutura de falha integra a faixa estrutural litosférica PT 3 - Pitanga/Quatinguá/Jacutinga, de origem Eo-Devonianas reativadas até o fim do Cretáceo, identificada por Soares (1991).

A estrutura geológica, através dos falhamentos, exerce importante controle na disposição dos canais de drenagem da Bacia do Rio Quatorze (PAISANI et al., submetido). O Rio Quatorze e seu principal tributário, Lajeado Grande (Figura 2), exibem traçado ajustado à inclinação dos planos de acamamento dos derrames de basalto na direção NE. Os demais tributários são controlados por fraturamentos e em menor número por falhamentos.

As fraturas da área de estudo estão orientadas principalmente para o quadrante NW $(64,31 \%)$, com

TABELA 1 - OCORRÊNCIA DE TIPOS DE EIXO DE DRENAGEM SUAVE E ÍNGREME EM CABECEIRAS DA BACIA DO RIO QUATORZE

\begin{tabular}{ccc}
\hline \multirow{2}{*}{$\begin{array}{c}\text { Tipo de Eixo de } \\
\text { Drenagem }\end{array}$} & Número & Percentual \\
\cline { 2 - 3 } & 154 & 81,05 \\
Suave & 36 & 18,95 \\
\hline
\end{tabular}




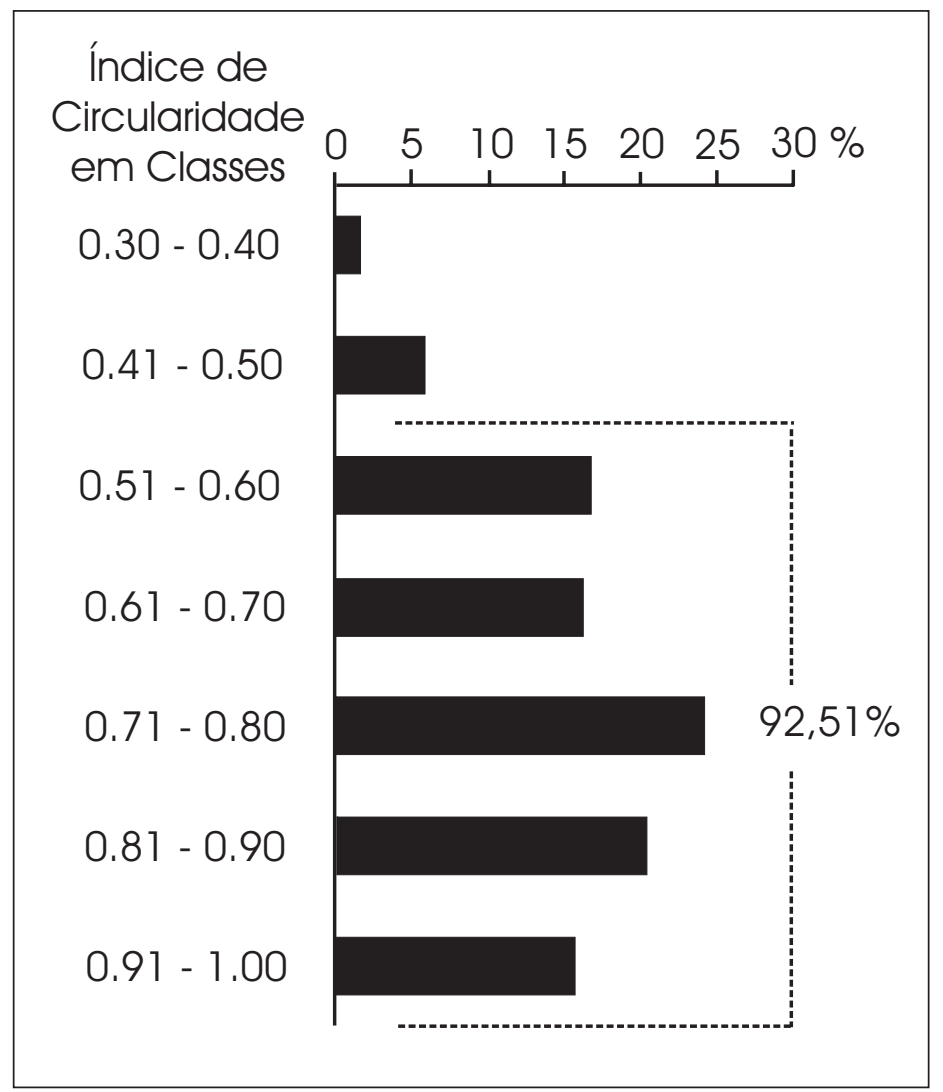

FIGURA 3-DISTRIBUIÇÃO DE FREQÜÊNCIA DOS VALORES DO ÍNDICE DE CIRCULARIDADE POR CLASSE (ADAPTADO DE PAISANI; GEREMIA, 2005)

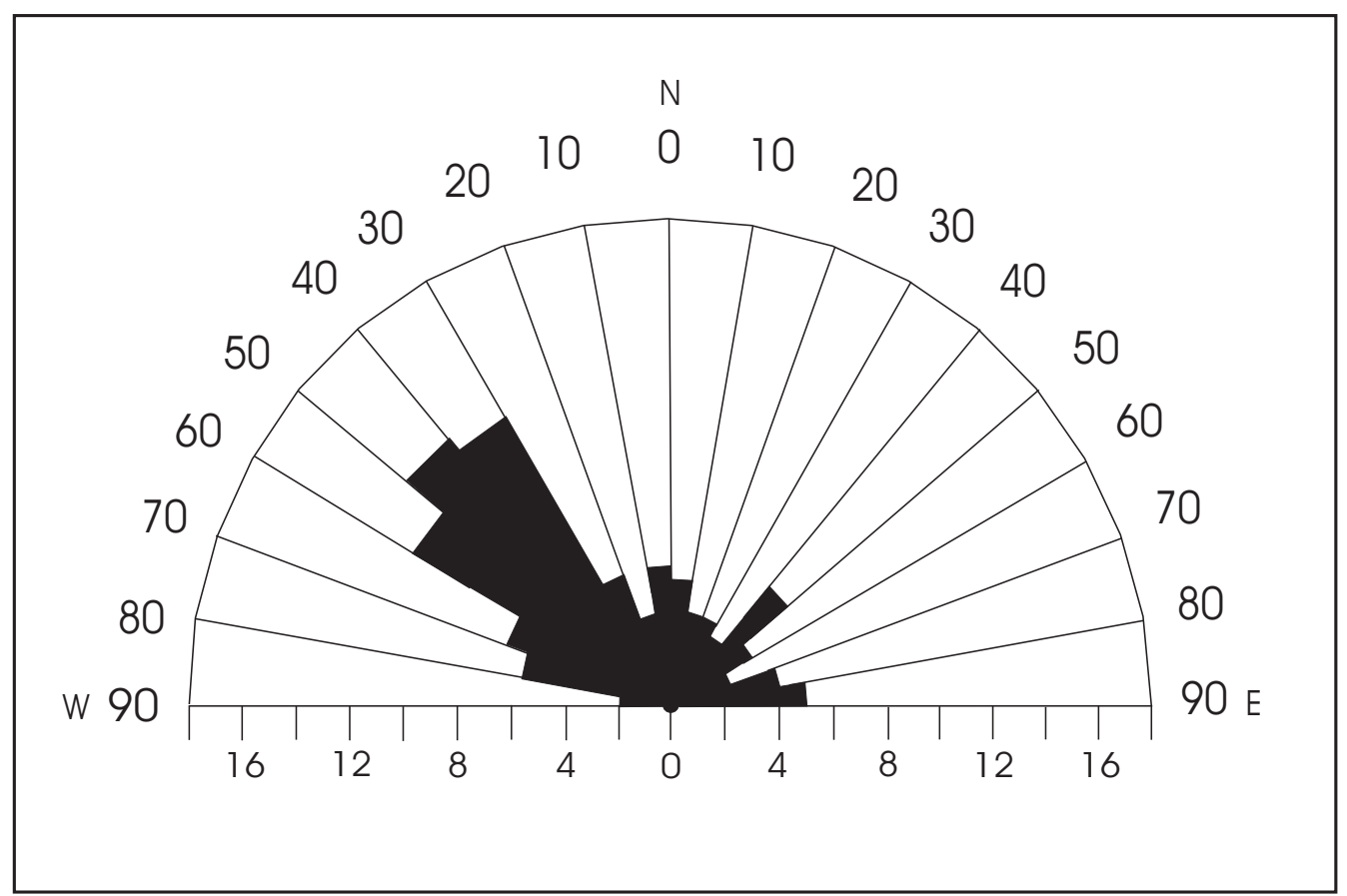

FIGURA 4 -DIAGRAMA DE ROSETA COM A ORIENTAÇÃO DAS FRATURAS DA BACIA DO RIO QUATORZE (ADAPTADO DE PAISANI et al., 2005) 
PAISANI, J. C. et al. Cabeceiras de drenagem da bacia do Rio Quatorze...

TABELA 2 - ORIENTAÇÃO DE EIXOS DE DRENAGEM E ALINHAMENTO DE CABECEIRAS NA BACIA DO RIO QUATORZE

\begin{tabular}{lccc}
\hline \multicolumn{1}{c}{ Critério } & Direções & N Casos $^{\circ}$ & Porcentual \\
\hline \multicolumn{1}{c}{$\begin{array}{c}\text { Eixos de Drenagem } \\
\text { das Cabeceiras }\end{array}$} & N 30-70 W & 29 & 15,26 \\
Alinhamento de & N 40-50 E & 8 & 4,21 \\
\cline { 2 - 4 } Cabeceiras & N 30 - 70 W & 66 & 34,74 \\
& N 40 - 50 E & 13 & 6,84 \\
\hline Total & & 116 & 61,05
\end{tabular}

classe modal na direção N 30 - 70 W (Figura 4). No quadrante oposto, apesar de registrar menor número de orientação de fraturas, há predomínio de fraturas orientadas na direção N 40-50 E. A classe modal e essa direção são concebidas como a principal família de fraturas da bacia do Rio Quatorze, que em campo mostram-se verticais com densidade de até 8 fraturas. $\mathrm{m}^{-2}$ (PAISANI et al., 2005).

O controle estrutural foi verificado registrando-se o percentual total de cabeceiras com eixo de drenagem ou alinhamentos nessas direções. Em relação ao total de 190 cabeceiras de drenagem, 116 (61,05\%) estão alinhadas ou exibem eixo de drenagem dispostos na mesma direção que a principal família de fraturas (Tabela 2). Destas, 90 (77,59\%) estão no domínio geomorfológico superfície aplainada de topo e apenas 26 (22,41\%) no domínio fundo de vale dissecado. Verifica-se que a maioria das cabeceiras é controlada por fraturamentos. A comparação direta entre orientação de fraturas e eixos de drenagem não se mostrou satisfatória, fato já constatado por Avelar e Coelho Netto (1992), revelando uma correlação estatística não linear.

Diante das limitações dos critérios utilizados na identificação do controle estrutural, não significa que as demais cabeceiras $(38,95 \%)$ deixaram de ser controladas por fraturas. Elas podem exibir orientações de eixos de drenagem e da disposição em alinhamentos coincidentes com as direções das demais fraturas.

\section{CONCLUSÕES}

O levantamento das propriedades morfológicas das cabeceiras de drenagem revelou que se tratam de feições circulares rasas, com eixo de drenagem suave e que ocorrem em sua maioria no domínio geomorfológico superfície aplainada de topo $(76,32 \%)$. Comparando com as cabeceiras de drenagem descritas no médio vale do Rio Paraíba do Sul, substrato contendo rochas cristalofilianas, constata-se significativas diferenças (MOURA et al., 1991).

A análise de controle estrutural revelou que a maioria das cabeceiras de drenagem $(61,05 \%)$ se mostra alinhada ou exibe eixo de drenagem orientados na mesma direção que a principal família de fraturas do basalto. No geral, os resultados demonstram que a origem das cabeceiras é determinada pela estrutura geológica da bacia do Rio Quatorze, SW - Paraná, possivelmente pelas fraturas verticais do basalto.

No que se refere à evolução das cabeceiras de drenagem, não se sabe em que momento da história evolutiva da bacia essas feições geomorfológicas se estabeleceram na paisagem geomorfológica. Por outro lado, a distribuição espacial sugere que as cabeceiras de drenagem são mais recentes que os relevos residuais identificados na superfície aplainada de topo, embora a formação dos domínios geomorfológicos da área de estudo ainda seja mal compreendida.

\section{AGRADECIMENTOS}

Agradecemos ao CNPq e à Pró-Reitoria de Pesquisa e Pós-Graduação da Unioeste pela bolsa de iniciação científica, bem como à Emater-Fco Beltrão pelo empréstimo de planímetro polar e curvímetro analógico. 


\section{REFERÊNCIAS}

ALVES, J. M. P.; CASTRO, P. T. A. Influência de feições geológicas na morfologia da bacia do Rio do Tanque (MG) baseada no estudo de parâmetros morfométricos e análise de padrões de lineamentos. Revista Brasileira de Geociências, v. 33, n. 2, p.117-124, 2003.

AVELAR, A. S.; COELHO NETTO, A. L. Fraturas e desenvolvimento de unidades geomorfológicas côncavas no médio vale do Rio Paraíba do Sul. Revista Brasileira de Geociências, v.22, n.2, p.222-227, 1992.

BIGARELLA, J. J.; MOUSINHO, M. R.; SILVA, J. X. Considerações a respeito da evolução das vertentes. Boletim Paranaense de Geografia, n. 16/17, p. 85-116, 1965.

et al. Estrutura e origem das paisagens tropicais e subtropicais. v. 3. Florianópolis: EdUFSC, 2003, p. 1.436.

CAMARGO, G. Processos de erosão no centro e sul do Segundo Planalto Paranaense: evolução de encosta e influência da erosão subterrânea na expansão de voçorocas. Florianópolis, 1998. 210 f. Dissertação (Mestrado em Geografia), Universidade de Santa Catarina.

CHORLEY, R. J.; KENNEDY, B. Physical geomgraphy: a systems approach. Prentice Hall International Inc., 1971. p.370.

CHRISTOFOLETTI, A. Análise morfométrica de bacias hidrográficas. Notícias Geomorfológicas, v.9, n.18, p.10-34, 1969.

p.188

Geomorfologia. São Paulo: Edgard Blücher, 1980.

PEREZ FILHO, A. P. Estudos sobre a forma de bacias hidrográficas. Boletim de Geografia Teorética, v. 5, n. 9/10, p. 83-92, 1975.

COELHO NETTO, A. L. Evolução de cabeceiras de drenagem no médio vale do Rio Paraíba do Sul (SP/RJ): a formação e o crescimento da rede de canais sob controle estrutural. Revista Brasileira de Geomorfologia, n. 2, p. 69-100, 2003.

DIETRICH, W. E.; DUNNE, T. The channel head. In: BEVEN, K.; KIRKBY, M. J. (Ed.). Channel network hydrology. John Wiley \& Sons, 1993. p.175-219.

FERNANDES, N. F. Hidrologia subsuperficial e propriedades físico-mecânicas dos "complexos de rampas" - Bananal (SP). 1990. 151 f. Dissertação (Mestrado em Geologia) - Instituto de Geociência, Programa de Pós-Graduação em Geologia, Rio de Janeiro, Universidade Federal do Rio de Janeiro.

FILIZOLA, H. F.; BOULET, R. Evolution and opening of closed depressions developed in a quartz-kaolinitic sedimentary substratum at Taubaté basin (São Paulo, Brazil), and analogy to the slope evolution. Geomorphology, n. 16, p.77-86, 1996.

FODOR, R. V.; MCKEE, E. H.; ROISENBERG, A. Age distribution of Serra Geral (Paraná) flood basalts, southern Brazil. Journal of South American Earth Sciences, v. 2, n. 4, p. 343-349, 1989.
GERARDI, L. H. O.; SILVA, B. C. N. Quantificação em geografia. São Paulo: DIFEL, 1981. p. 161.

GEREMIA, F.; PAISANI, J. C. Mapa morfoescultural da bacia do Rio Quatorze. Francisco Beltrão: Unioeste, 2005. 1 mapa, color.; 118,9 x 84,1cm. Escala 1:24.000.

KIRKBY, M. L. Hillslope hydrology. John Wiley \& Sons, 1978. p. 389.

LOCZY, L.; LADEIRA, E. A. Geologia estrutural e introdução à geotectônica. São Paulo: Edgard Blücher, 1980. p. 528.

LÖFFLER, E. Karts features in igneous rocks in Papua New Guinea. In: DAVIES, J. L.; WILLIAMS, M. A. J. (Ed.). Landform evolution en Australian. Canberra: ANU Press, 1978. p. 238249.

MAACK, R. Geografia física do Paraná. Rio de Janeiro: José Olympio, 1981. p. 442.

MARTINS, G. Caracterização climática do sudoeste do Paraná segundo Maack. In: ENCONTRO DE GEOGRAFIA, 8., ENCONTRO DE GEOGRAFIA DO SUDOESTE DO PARANÁ, 2., 2003, Francisco Beltrão. Anais... Francisco Beltrão: Unioeste, 2003. p. 29-31.

MEIS, M. R. M.; MONTEIRO, A. M. F. Upper quaternary "rampas": Doce river valley, southeastern Brazilian plateau. Zeitschrift für Geomorphologie, v. 23, n. 2, p.132-151, 1979.

MELO, M. S. et al. Sedimentação quaternária no espaço urbano de Ponta Grossa (PR). Geociências, v. 22, n. 1, p. 3342, 2003.

MELLO, C. L. Fácies sedimentares, arquitetura deposicional e relações morfoestratigráficas em um sistema de leques aluviais holocênicos: aloformação manso - médio Vale do Rio Paraíba do Sul (SP/RJ). Rio de Janeiro, 1992. 188 f. Dissertação (Mestrado em Geologia) - Instituto de Geociência, Programa de Pós-Graduação em Geologia, Universidade do Rio de Janeiro.

MONTGOMERY, D. R.; DIETRICH, W. E. Source áreas, drainage density and channel initiation. Water Resources Research, v. 25, n. 8, p.1907-1918, 1989.

MOURA, J. R. S.; PEIXOTO, M. N. O.; SILVA, T. M. Geometria do relevo e estratigrafia do quaternário como base à tipologia de cabeceiras de drenagem em anfiteatro - médio Vale do Rio Paraíba do Sul. Revista Brasileira de Geociências, v. 21, n. 3, p. 255-265, 1991.

NARDY, A. J. R. et al. Caracterização litoquímica e aspectos petrológicos de rochas vulcânicas da Formação Serra Geral: região centro-sul do estado do Paraná. Geociências, São Paulo, v. 12, n. 2, p. 275-313, 1993.

OLIVEIRA, M. A. T. Morphologie dês versants et ravinements: héritages et morphogénèse actualle dans une région de socle tropical. Le cas de Bananal, São Paulo, Brésil. Paris, 1992. 401 f. Tese (Doutorado em Geografia) - Universidade de Paris IV - Sorbonne. 
OLIVEIRA, M. A. T.; MEIS, M. R. M. Relações entre geometria do relevo e formas de erosão linear acelerada - Bananal (SP). Geociências, v. 4, p. 87-99, 1985.

PEREIRA, K. N. Identificação de solos coluviais em áreas de cabeceira de drenagem: Cerro do Touro, Campo Alegre (SC). Revista Geosul - Departamento Geociência UFSC, v. 14, n. 27, p. 476-481, 1998.

et al. Caracterização paleohidrológica de estruturas sedimentares quaternárias através de análises macroscópicas e microscópicas: do registro sedimentar local aos indícios de mudanças globais. Pesquisas em Geociências, v. 28, n. 2, p. 183-195, 2001.

PAISANI, J. C. Análise da estruturação da rede de drenagem da bacia do Rio Nhundiaquara - PR. Curitiba, 1995, $84 \mathrm{f}$. Monografia - Departamento de Geografia, Universidade Federal do Paraná.

Hidrologia de encosta e desenvolvimento de canais de drenagem. In: ENCONTRO DE GEOGRAFIA, 7., ENCONTRO DE GEOGRAFIA DO SUDOESTE DO PARANÁ (GEOGRAFIA NA CONTEMPORANEIDADE), 1., Francisco Beltrão. Anais.... Francisco Beltrão:Unioste, 2002. p. 21-23.

. et al. Análise de lineamentos geomorfológicos na bacia do Rio Quatorze - sudoeste do Paraná. Revista Varia Scientia, v. 5, n. 10, 2005. No prelo.

PAISANI, J. C.; GEREMIA, F. Utilização do índice de circularidade na determinação da forma de concavidades (cabeceiras de drenagem e depressões fechadas) na bacia do Rio Quatorze (PR). In: ENCONTRO DE GEOGRAFIA, 10., ENCONTRO DE GEOGRAFIA DO SUDOESTE DO PARANÁ, 4., 2005, Francisco Beltrão. Resumos Expandidos. Francisco Beltrão: Unioeste, 2005. p. 156-158.

PAISANI, J. C.; OLIVEIRA, M. A. T. Identificação de paleossolos em áreas de cabeceira de drenagem: o caso da Colônia Quero-Quero, Palmeira (PR). Revista Geosul - Departamento Geociência UFSC, v. 14, n. 27, p. 470-475, 1998.
Dinâmica da área de contribuição para a formação de escoamento superficial saturado - cabeceira de drenagem da Colônia Quero-Quero - Palmeira (PR). Geociências, v. 18, n. 2, p. 261-284, 1999.

. Desenvolvimento de incisão erosiva (voçoroca) descontínua e desconectada da rede hidrográfica em área de cabeceira de drenagem: o caso da Colônia Quero-Quero - Palmeira (PR). Revista Brasileira de Geociências, v. 31, n. 1, p. 51-58, 2001.

PENCK, W. Morphological analysis of land forms: a contribution to physical geology. London: Macnillan and Co., 1953. p. 429.

PETRI, S. Aerogeologia. In: MENDES, J. C.; BIGARELLA, J. J.; SALAMUNI, R. (Orgs.). Estratigrafia e sedimentologia, geologia estrutural e aerofotogeologia. Brasília: Ministério da Educação e da Cultura/Instituto Nacional do Livro, 1972. p. 49.

SCHEIDEGGER, A. E. Tectonic processes and geomorphological design. Tectonophysics, v. 126, p. 285-300, 1986.

SCHNEIDER, R. L. et al. Revisão estratigráfica da bacia do Paraná. In: CONGRESSO BRASILEIRO DE GEOLOGIA, 28., 1974, Porto Alegre. Anais... Porto Alegre: SBG, 1974. p. 4165.

SOARES, P. C. Tectônica sinsedimentar na bacia do Paraná - controles. Curitiba, 1991. 131 f. Tese - Departamento de Geologia, Universidade Federal do Paraná.

THOMAS, M. F. Geomorphology in the tropics: a study of weathering and denudation in low latitudes. Wiley, 1994. p. 460.

TSUKAMOTO, Y.; OTHA, T.; NOGUCHI, H. Hydrological and geomorphological studies of debris slides on florested hillslopes in Japan. International Association of Hidrological Scientists Publication, v. 137, p. 89-98, 1982. 